\title{
The Effectiveness of Cross Training on Mental Toughness, Development of Special Physical Abilities, and The Degree of Skilled Performance in Aerobic Gymnastics
}

\section{Dr . khaled abuwarda}

\section{Introduction and research problem:}

The field of sports has recently witnessed further developments in training methods aiming to achieve the goal of the training process through making full use of modern methods and techniques in training. As a result, rather than relying only on their personal experience, the use of science and modern technological means in the training process has become a defining characteristic of successful trainers. Success in training has become the ability to reach the player to the highest level in all physical, skill, tactical, physiological and psychological aspects without overloading him or being exposed to injuries resulting from training errors and the ability to continue training with the same efficiency.

Cross-training is one of the modern organizational forms in the field of sports training and it is a strategy used by coaches to organize training programs and fitness activities, through which the largest number of various activities and physical challenges are used so that the player continues to acquire and achieve the requirements and goals of overall fitness in a safe manner and lead to improvement in the skilled side, as it is an organizational form for methods and means of sports training, as it depends on diversity in practicing various activities and sports related to the specialized activity practiced in order to maintain the physical, physiological and psychological requirements of the players. (Hassan.2004) (Brislin.1998)

Taylor (2000), Pedersen (2000), and Hasan (2004) agree that crosstraining is important for development of general and specific physical capabilities, as it allows for additional effort to be performed during basic sport with less risk of over-training and burnout. Its use can reduce the chances of injuries as cross-training allows the use of additional muscle groups that are not involved in basic sports, and cross-training is useful as an activity in warm-up and cool-down exercises where it offers psychological and mental comfort. 
Brislin (1998) and Matt Fitzgerald (2010) show that cross-training includes both weight training using fewer iterations and large iterations and plyometric exercises, which work to build body strength and develop muscle strength and muscular capacity, as well as include aerobic endurance activities, including hydro jogging exercises, the use of a moving belt and a stationary training wheel, as well as anaerobic endurance activities, including sprint training, and therefore many high-level, Olympic and professional runners used it to improve their performance in specialized sports activity.

Fiona Hayes (1998) adds that the most important characteristic of cross-training is the variety of exercises that exist in the program, which maintain excitement for a long time, and the upgrading of different muscle groups in different ways.

Aerobic Gymnastics is one of the seven types of gymnastics registered with the International Gymnastics Federation and the first world championships were held in France in 1995, and it is a competitive sporting activity that uses a unique combination of aerobic choreography and gymnastic elements. Also defined as the ability to continuously perform with high-intensity movement patterns that arise from traditional aerobic exercise, competitive exercise must demonstrate creativity with the perfect combination of all movements, music and expression. (FIG, 2017)

The Egyptian Gymnastics Federation introduced "aerobic gymnastics" within the local competitions in 2017 as a type of modern gymnastics, and is distinguished by that it relies on the movements of jumping and sports dance accompanying the music and does not perform any rollers or flips', and in it there are many types of competitions to include (individual competitions, double competitions, triple competitions, group competitions), the duration of the exercise in aerobic gymnastics ranges from 60-90 seconds, and the movements in these exercises focus on showing the strength, flexibility and high physical fitness of the participants, and it consists of one device that is the ground device and has special characteristics, it must be used Exercise Seven basic steps of aerobic exercise, variations in dance moves and at least four difficulty elements with a maximum of 10 competitive exercise items. (FIG, 2017) (EGF, 2018)

The researcher noticed through his work as a referee and trainer of aerobic gymnastics that there is a weakness in the level of 
performance of some basic skills that require jumping up, including group jump and lib movements (GROUP C - JUMPS AND LEAPS), as the researcher think that may attribute to the low availability of some physical abilities that qualifies the player from the quality of performance, as it is noticed that these skills require the availability of some physical abilities, including the explosive power of the muscles of the legs and arms, the speed of access to the place of implementation of the skill, as well as the motor speed of the skill and these physical abilities may qualify the player to reach the highest possible height at an appropriate speed, in addition to the lack of qualified agility from the possibility of changing the position of the body on the ground and in the air during the proper technical performance, as well as the training modality that characterizes some training programs in the field of gymnastics training, and there are some training programs that are applied in a random and unorganized manner and away from the scientific basis of training, that can overload a player, and the lack of diversity in the use of modern devices and means, which may cause boredom and the player's reluctance to attend training.

Simon Middleton et al (2004), Gould et al. (2002) and Shimon (2001) indicate that mental toughness plays an effective role in controlling the ideal state of performance as it aims to build mental and emotional strength, and mental toughness is the player's ability to confront and deal with all kinds of physical, mental and emotional pressures so that it becomes more interactive in competition, which is reflected in the mastery of sports skills and at the same time reduces the risks of sports injuries and emotional withdrawal.

And both John Lefkowits, (2003) and James Lowther (2002) indicate that mental toughness is the ability to stabilize ideal performance when competition pressures intensify, and this requires good tactic and mental skills, and they add that the instability of performance during competitions is primarily attributable to Psychological variables, which comes in the forefront of the mental toughness variables, bearing in mind that mental toughness is an acquired trait away from the factor of heredity.

Where psychological skills that reflect mental toughness play a big role in achieving victory and superiority, and in this regard Hayley Merrett (2004) indicates that gymnasts must be distinguished by 
mental toughness as one of the most important decisive factors in winning.

Both Middelton (2004) and John Lefkowits (2003) agree that mental toughness is not only a mental trait, but also a physical and emotional trait. Mental toughness is not having the ability to beat your competitors or stand out in nervous calm, but it means reaching the ultimate ideal performance of your skills and your talent regardless of competition conditions, and physical toughness is the possession of a high level of fitness during competition, while emotional rigidity means the ability to emotional control during intense and stressful competitive situations.

By reviewing the related studies in the field of aerobic gymnastics, which he was able to reach, he found that some of them dealt with and predict injuries in aerobic gymnastics, such as the study of Abalo Núñez, R., et al (2013), the study of Abalo, R., Gutiérrez-Sánchez (2013) and the study Abalo-Núñez, R., (2018) and D'Anna, C., (2019), and others have addressed performance standards in aerobic gymnastics such as Mariana, M., (2014), Pop, C., (2014) and others. Alves, CRR, et al (2015) and the study of Salem, Rehab (2018), and with a review of studies that dealt with mental toughness in the sports field, some of them found that they dealt with mental toughness and its relationship to skill level, such as the study of Musa, Salwa (2006), the study of Al-Shami, Muhammad (2007) ), Study of Ibrahim, Muhammad (2015), Study of Ibrahim, Amira (2016), Study of Salih, Mahmoud (2018). This prompted the researcher to conduct this study that aims to develop an integrated training program using crosstraining on mental toughness in (self-confidence - negative energy attention control - visual perception control - motivation level - positive energy - direction control), and the development of special physical capabilities (strength Explosiveness - agility - balance - flexibility) and the degree of skillful performance of young aerobic gymnasts under the age of 14 , as it is the first stage in which the young person can choose his movement that fits his capabilities and abilities, and that age is the first building block in preparing the gymnast with the aim of reaching international standards.

Research objective: 
The research aims to identify the effectiveness of using cross-training on mental toughness in (self-confidence - negative energy - attention control - visual perception control - motivation level - positive energy - Attitude Control), and the development of special physical capabilities (explosive strength - agility - balance - flexibility) and the degree of skillful performance of aerobic gymnasts.

\section{Research hypotheses:}

- There are statistically significant differences between the pre and post measurements in mental toughness, the level of special physical abilities, and the degree of skill performance of aerobic gymnasts in favor of the post measurement.

\section{Terms used in the search:}

- Cross Training:

It is an organizational form of methods and means of sports training based on diversity in the practice of different activities and sports related to the specialized activity practiced, aiming to improve the level of the components of the training case, through the multiplicity of the use of modern devices, tools and techniques in the field of sports training. (Guid, 20004)

\section{- Mental Toughness:}

-It is the ability to stabilize the ideal performance when the competition pressures that the player is exposed to, and it requires good psychology and mental skills (Jolly, 2003)

-It is the continuation of positive, constructive thinking quietly while avoiding defensiveness, and not giving up, with realism in performance (Shimon, 2007)

\section{Search procedures:}

\section{Research Methodology:}

The researcher used the experimental method using the design of one experimental group (pre-measurement - post-measurement).

\section{The research sample:}

The research sample was deliberately chosen from the youth of gymnastics under 14 years old at the Suez Canal Authority Club in Port Fouad, and the basic experimental sample included 4 players, and the two researchers also used 4 players from outside the basic 
research sample but from the same research community to conduct the exploratory study and the scientific treatment of the tests used.

Table (1): Characteristics of the research sample in the variables of height, weight, age and training age $n=4$

\begin{tabular}{lccccc}
\hline Variables & $\begin{array}{c}\text { Measuring } \\
\text { unit }\end{array}$ & $\begin{array}{c}\text { Arithmetic } \\
\text { mean }\end{array}$ & $\begin{array}{c}\text { Standard } \\
\text { deviation }\end{array}$ & Median & Skewness \\
\hline Age & Year & 13.850 & 0.229 & 13.900 & -0.864 \\
\hline Length & $\mathrm{Cm}$ & 169.500 & 1.118 & 169.500 & 0.000 \\
\hline Weight & $\mathrm{Kg}$ & 57.000 & 2.739 & 57.500 & -0.632 \\
\hline Training age & Year & 5.625 & 0.650 & 5.500 & 0.370 \\
\hline
\end{tabular}

It is evident from Table (1) that the Coefficient Of skewness were limited to $(-0632,0.370)$ for the research sample, and these values were limited between (3), which indicates the homogeneity of the research sample members in the variables of height, weight, age and training age before the experiment.

\section{Methods of data collection:}

First: Height measurement: Height was measured using a record holder to the nearest $1 \mathrm{~cm}$.

Second: Measuring weight: Weight was measured using a medical scale to the nearest $1 \mathrm{~kg}$.

Third: the psychological performance list test to determine mental toughness:The researcher applied the psychological performance list test (psychological performance inventory) to determine the mental toughness of James Loehr (1986), after preparing it and translating it into Arabic, and it includes (7) psychological determinants: (Selfconfidence - negative energy - control of attention - visual perception control - motivation level - energy Positivity - governing the direction), for each specifier (6) phrases, and thus the number of statements is (42) a statement and the total sum of the scale is (210) degrees, with five features (always - often - sometimes - rarely - never). If the statement is fulfilled, the student gets (5) points, and if the statement is not fulfilled, the student gets (1) point, and the scale has positive expressions starting from (5-4-3-2-1) and negative expressions starting from (1-2-3-4-5), and there is a form for emptying the scale, and the scale was translated into Arabic (annex No. 1) and applied in the Egyptian environment in the study of Ismail, Magda, Fouad, Jehan (2006), Rashad, Mervat (2006), where they reached high validity results. It ranged between $(0.72,0.96)$.

Fourth: Expert opinion poll: 
The researcher has designed a survey to be presented to a group of experts in aerobic gymnastics for the purpose of determining the special physical abilities as well as choosing the necessary tests to measure those capabilities. The researcher took into account that these tests have a special characteristic of gymnastics. The expert opinion poll included five specialists in aerobic gymnastics, annex No. (2).

According to the opinions of experts, the special physical abilities of aerobic gymnastics and their tests were determined, and the researcher satisfied a rate of $60 \%$ to $100 \%$ and reached 4 special physical abilities and the number of 8 tests annex No. (3), which are:

\section{Explosive strength \\ - Standing Broad Jump Test \\ - Standing Vertical Jump test \\ 2. Agility \\ - Quadrant Jump Test (10 sec) \\ - Squat Thrusts Test (10 sec)}

3. Balance:

- Modified Bass Test

- Handstand Walk test

\section{Flexibility}

- Sit and Reach Test

- Bridge Test (dome)

\section{Fifth: measuring the level of skill performance:}

The level of skill performance of aerobic gymnasts (individual men) was measured, annex No. (4), using the jury method in accordance with International Arbitration Law guidelines by certified referees in the Egyptian Gymnastics Federation. (FIG, 2017) (EGF, 2018)

\section{Scientific transactions for Tests used:}

The two researchers conducted the scientific transactions for the tests - under research - from 1/7/2019 to 8/7/2019 to ensure the validity of those tests from a scientific point of view by calculating the stability of the tests by finding the Spearman correlation coefficient for rank differences by applying the tests and re-applying them after a oneweek period of time for a group of youth gymnasts, consisting of 4 players, from outside the research sample and from the same community, as shown in Table (2).

The validity of the tests was also calculated based on the method of validation of the differentiation by applying the tests to two groups, 
one of which is distinguished, consisting of (4) players, which is the same group used to find stability using the data of their first application, and the other group is not distinguished, consisting of (4) players, as shown in Table (3).

Table (2): Reliability coefficients for the tests under consideration $n=4$

\begin{tabular}{|c|c|c|c|c|c|c|c|}
\hline & \multirow{2}{*}{ Variables } & \multirow{2}{*}{$\begin{array}{c}\text { measure } \\
\text { unit }\end{array}$} & \multicolumn{2}{|c|}{$1^{\text {st }}$ applying } & \multicolumn{2}{|c|}{$2^{\text {nd }}$ applying } & \multirow{2}{*}{ Sig } \\
\hline & & & $\mathrm{X} 1$ & $\pm \mathrm{y} 1$ & $\mathrm{X} 2$ & $\pm \mathrm{y} 2$ & \\
\hline \multirow{2}{*}{ 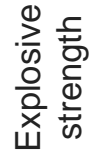 } & Vertical Jump & $\mathrm{Cm}$ & 28.50 & 1.29 & 28.00 & 1.63 & 0.80 \\
\hline & Standing Broad Jump & $\mathrm{Cm}$ & 126.8 & 1.10 & 126.6 & 1.03 & 0.85 \\
\hline \multirow{2}{*}{ 嚞 } & Squat Thrusts (10 sec) & Degree & 39.16 & 2.96 & 39.50 & 2.69 & 0.97 \\
\hline & Quadrant jump (10 sec) & Number & 10.75 & 0.95 & 10.50 & 1.29 & 0.92 \\
\hline \multirow{2}{*}{ 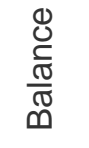 } & Modified Bass & Degree & 59.60 & 1.70 & 60.00 & 1.63 & 0.96 \\
\hline & Handstand Walk & Degree & 24.00 & 1.82 & 23.00 & 2.44 & 0.79 \\
\hline \multirow{2}{*}{$\begin{array}{l}\underset{\frac{Z}{\bar{Z}}}{\overline{\bar{a}}} \\
\frac{\mathbb{O}}{\square}\end{array}$} & Bridge (dome) & $\mathrm{Cm}$ & 78.33 & 1.49 & 78.00 & 1.15 & 0.96 \\
\hline & Sit and Reach & Degree & 6.66 & 0.47 & 6.83 & 0.68 & 0.85 \\
\hline
\end{tabular}

Table (2) indicates that the stability coefficients of the tests - under discussion -, by applying the Spearman Correlation coefficient, have been limited between ( 0.79 and 0.97 ), and all of them are high stability coefficients, which indicates the stability of these tests.

Table (3): Differentiation validity coefficients for the tests under consideration

$\mathrm{n} 1=\mathrm{n} 2=4$ 


\begin{tabular}{|c|c|c|c|c|c|c|c|}
\hline \multicolumn{2}{|c|}{ Physical tests } & \multirow{2}{*}{$\begin{array}{c}\text { distinctive } \\
7.80\end{array}$} & \multirow{2}{*}{$\begin{array}{c}\begin{array}{c}\text { less } \\
\text { distinctive }\end{array} \\
3.20\end{array}$} & \multirow{2}{*}{$\begin{array}{c}\text { distinctive } \\
39.00\end{array}$} & \multirow{2}{*}{$\begin{array}{c}\begin{array}{c}\text { less } \\
\text { distinctive }\end{array} \\
16.00\end{array}$} & \multirow[b]{2}{*}{1.00} & \multirow[b]{2}{*}{0.016} \\
\hline$\stackrel{0}{\geq}=$ & Vertical Jump & & & & & & \\
\hline 产妾 & $\begin{array}{l}\text { Standing Broad } \\
\text { Jump }\end{array}$ & 7.60 & 3.40 & 38.00 & 17.00 & 2.00 & 0.032 \\
\hline \multirow{2}{*}{ 交 } & $\begin{array}{l}\text { Squat Thrusts } \\
(10 \mathrm{sec})\end{array}$ & 7.60 & 3.40 & 38.00 & 17.00 & 2.00 & 0.032 \\
\hline & $\begin{array}{l}\text { Quadrant jump } \\
\text { (10 sec) }\end{array}$ & 7.70 & 3.30 & 38.50 & 16.50 & 1.50 & 0.016 \\
\hline \multirow{2}{*}{ 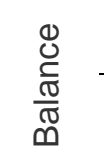 } & Modified Bass & 7.80 & 3.20 & 39.00 & 16.00 & 1.00 & 0.016 \\
\hline & Handstand Walk & 7.60 & 3.40 & 38.00 & 17.00 & 2.00 & 0.032 \\
\hline \multirow{2}{*}{$\begin{array}{l}\frac{\vec{y}}{\overline{\bar{a}}} \\
\frac{\bar{x}}{\square} \\
\frac{0}{4}\end{array}$} & Bridge (dome) & 7.70 & 3.30 & 38.50 & 16.50 & 1.50 & 0.016 \\
\hline & Sit and Reach & 7.60 & 3.40 & 38.00 & 17.00 & 2.00 & 0.032 \\
\hline
\end{tabular}

It is evident from Table (3) that the value of $(y)$ calculated by applying the Mann-Whitney test to indicate the differences between the distinguished group and the least distinguished group in the physical tests - under discussion - is limited to between (2.00 and 1.50), and all of them are statistically significant at a level of significance (0.05) meaning So that the differences between the distinguished group and the less distinguished group in these variables are real and in favor of the distinguished group, and this indicates that these tests are valid, i.e. they measure what they were designed for.

\section{The proposed training program:}

The researcher prepared the proposed training program by employing cross-training as one of the modern organizational forms that uses various activities and non-traditional means to provide opportunities for excitement and suspense, by reviewing previous studies and references specialized in cross training and references to sports training science, annex No. (5), This resulted in the following activities (plyometric exercises, water jogging exercises, sand training, rope jumping exercises, resistance exercises with elastic bands.

\section{Exploratory study:}

The two researchers conducted the exploratory study from $7 / 9 / 2019$ to $12 / 7 / 2019$ in order to ensure the safety and validity of the tools and devices used, and to codify the physical preparation exercises, skill 
preparation and cross-training exercises under discussion that were included in the training program. This was done using a sample of 3 players from the same research community and outside the basic research sample.

\section{Basic experiment:}

- pre-measurements:

Pre-measurements were made on the basic research sample in the Suez Canal Authority Club Hall in Port Said Governorate during the period from $7 / 14 / 2019$ to $7 / 15 / 2019$.

\section{- Implementing the training program}

The training program was applied to the basic research group using the method of cross exercises in the general physical preparation part of the training program, where the performance of these exercises per week ranged between (99 minutes - 180 minutes) for a period of 8 weeks during the period from $7 / 20 / 2019$ to $14 / 9 / 2019$, by five training units per week.

\section{- Post-measurements}

The pot-measurements were made at the same location and in the order followed in the pre-measurements, in the period from 9/16/2019 to $9 / 17 / 2019$.

\section{Statistical treatment:}

The researcher used the SPSS V24 statistical program package in treating the data statistically by using the Wilcoxon signed-ranks test equations to indicate the differences, the arithmetic mean, the standard deviation, the largest and the lowest value.

\section{Presentation and discussion of results:}

Table (4): The significance of the differences between the pre and post measurements in the research variables using the Wilkson test 


\begin{tabular}{|c|c|c|c|c|c|c|c|c|c|}
\hline & \multirow[t]{2}{*}{ Variables } & \multicolumn{2}{|c|}{$\begin{array}{l}\text { Ranks } \\
\text { number }\end{array}$} & \multicolumn{2}{|c|}{$\begin{array}{c}\text { Ranks } \\
\text { Average }\end{array}$} & \multicolumn{2}{|c|}{ Sum of ranks } & \multirow{2}{*}{$\begin{array}{l}\text { Calculate } \\
\text { d z Value }\end{array}$} & \multirow[t]{2}{*}{ Sig } \\
\hline & & - & + & - & + & - & + & & \\
\hline \multirow{8}{*}{ 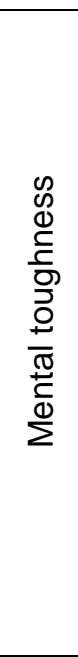 } & Self-Confidence & 0 & 5 & $\begin{array}{c}0.0 \\
0\end{array}$ & $\begin{array}{c}3.0 \\
0\end{array}$ & $\begin{array}{c}0.0 \\
0\end{array}$ & 15.00 & $2.07-$ & 0.038 \\
\hline & Negative energy & 0 & 5 & $\begin{array}{c}0.0 \\
0\end{array}$ & $\begin{array}{c}3.0 \\
0\end{array}$ & $\begin{array}{c}0.0 \\
0\end{array}$ & 15.00 & 2.07- & 0.038 \\
\hline & Attention Control & 0 & 5 & $\begin{array}{c}0.0 \\
0\end{array}$ & $\begin{array}{c}3.0 \\
0\end{array}$ & $\begin{array}{c}0.0 \\
0\end{array}$ & 15.00 & $2.06-$ & 0.039 \\
\hline & visual perception control & 0 & 5 & $\begin{array}{c}0.0 \\
0\end{array}$ & $\begin{array}{c}3.0 \\
0\end{array}$ & $\begin{array}{c}0.0 \\
0\end{array}$ & 15.00 & $2.07-$ & 0.038 \\
\hline & Motivation level & 0 & 5 & $\begin{array}{c}0.0 \\
0\end{array}$ & $\begin{array}{c}3.0 \\
0\end{array}$ & $\begin{array}{c}0.0 \\
0\end{array}$ & 15.00 & $2.18-$ & 0.034 \\
\hline & Positive energy & 0 & 5 & $\begin{array}{c}0.0 \\
0\end{array}$ & $\begin{array}{c}3.0 \\
0\end{array}$ & $\begin{array}{c}0.0 \\
0\end{array}$ & 15.00 & $2.02-$ & 0.043 \\
\hline & Attitude Control & 0 & 5 & $\begin{array}{c}0.0 \\
0\end{array}$ & $\begin{array}{c}3.0 \\
0\end{array}$ & $\begin{array}{c}0.0 \\
0\end{array}$ & 15.00 & 2.04- & 0.041 \\
\hline & Total test & 0 & 5 & $\begin{array}{c}0.0 \\
0\end{array}$ & $\begin{array}{c}3.0 \\
0\end{array}$ & $\begin{array}{c}0.0 \\
0\end{array}$ & 15.00 & $2.22-$ & 0.034 \\
\hline \multirow{8}{*}{ 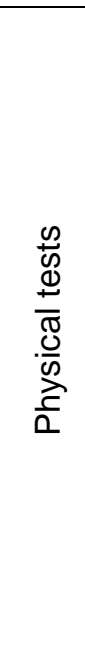 } & Vertical Jump & 0 & 5 & $\begin{array}{c}0.0 \\
0\end{array}$ & $\begin{array}{c}3.0 \\
0\end{array}$ & $\begin{array}{c}0.0 \\
0\end{array}$ & 15.00 & 2.07- & 0.038 \\
\hline & Standing Broad Jump & 0 & 5 & $\begin{array}{c}0.0 \\
0\end{array}$ & $\begin{array}{c}3.0 \\
0\end{array}$ & $\begin{array}{c}0.0 \\
0\end{array}$ & 15.00 & $2.07-$ & 0.038 \\
\hline & Squat Thrusts (10 sec) & 0 & 5 & $\begin{array}{c}0.0 \\
0\end{array}$ & $\begin{array}{c}3.0 \\
0\end{array}$ & $\begin{array}{c}0.0 \\
0\end{array}$ & 15.00 & $2.06-$ & 0.039 \\
\hline & Quadrant jump (10 sec) & 0 & 5 & $\begin{array}{c}0.0 \\
0\end{array}$ & $\begin{array}{c}3.0 \\
0\end{array}$ & $\begin{array}{c}0.0 \\
0\end{array}$ & 15.00 & 2.07- & 0.038 \\
\hline & Modified Bass & 0 & 5 & $\begin{array}{c}0.0 \\
0\end{array}$ & $\begin{array}{c}3.0 \\
0\end{array}$ & $\begin{array}{c}0.0 \\
0\end{array}$ & 15.00 & $2.12-$ & 0.034 \\
\hline & Handstand Walk & 0 & 5 & $\begin{array}{c}0.0 \\
0\end{array}$ & $\begin{array}{c}3.0 \\
0\end{array}$ & $\begin{array}{c}0.0 \\
0\end{array}$ & 15.00 & $2.02-$ & 0.043 \\
\hline & Bridge (dome) & 0 & 5 & $\begin{array}{c}0.0 \\
0\end{array}$ & $\begin{array}{c}3.0 \\
0\end{array}$ & $\begin{array}{c}0.0 \\
0\end{array}$ & 15.00 & $2.04-$ & 0.041 \\
\hline & Sit and Reach & 0 & 5 & $\begin{array}{c}0.0 \\
0\end{array}$ & $\begin{array}{c}3.0 \\
0\end{array}$ & $\begin{array}{c}0.0 \\
0\end{array}$ & 15.00 & 2.12- & 0.034 \\
\hline \multicolumn{2}{|c|}{ Degree of skilled performance } & 0 & 5 & $\begin{array}{c}0.0 \\
0\end{array}$ & $\begin{array}{c}3.0 \\
0\end{array}$ & $\begin{array}{c}0.0 \\
0\end{array}$ & 15.00 & 2.07- & 0.038 \\
\hline
\end{tabular}

The table (4) shows that the values of ( $z$ ) calculated by applying the Wilcoxon signed-ranks test to indicate the differences between the two measurements the pre and the post for the main research sample in the determinants of mental toughness (self-confidence - negative energy - attention control - visual perception control - motivation level - positive energy - The trend control) was limited to $(-2.02,-2.22)$ with levels of statistical significance that ranged between $(0.043,0.034)$, all of which are statistically significant, indicating that the differences between the pre and post measurements of the research sample were real differences in favor of the post measurement, and this indicates improvement The members of the experimental group in these variables, and the researcher attributes this to the proposed cross-training program, including exercises (plyometric exercises, 
water jogging exercises, sand training, sprint exercises, rope jumping exercises, resistance exercises with elastic ropes) that were applied in the general physical preparation part, in addition to the special physical preparation and skill preparation exercises, which helped to improve the determinants of mental toughness necessary for skillful performance, and this is consistent with what was indicated by Ismail, Magda and Fouad, Jihan (2006) that standardized training programs improve the determinants of mental toughness and thus raise the level of skill performance.

Lutfi, Muhammad and Muhammad, Ashraf (2003) point out that the use of cross-training affects the psychological aspect by getting rid of routine when training for only one activity, removing the feeling of boredom and monotony, and having some kind of psychological adaptation and increasing the effectiveness of training.

Chris, Sellars (1997) and Pritchard, Keith (2002) also agree that certain psychological features must be developed, which in turn contribute to the individual's ability to overcome the special obstacles associated with a particular sport activity or those particular obstacles associated with an individual's attempt to reach the highest level of this activity. Ray,Jolly(2003) asserts that mental toughness is a acquired trait that does not enter its genetics. These results are consistent with the study of Ibrahim, Shaban, Badr al-Din, and Tariq (2001) and the study of Al-Hadidi, Rabi '(2011) and the study of Shawky, Najia (2015) in that psychological skills can be developed through sports training.

The Table (4) shows that there are statistically significant differences between the pre-measurement and the post-measurement in favor of the post-measurement at a significance level of 0.05 in the physical variables (explosive strength, agility, balance, flexibility) and the researcher returns this positive change to the cross-training program that was applied to the research sample. And its effectiveness in achieving the highest levels of muscular contraction during the performance of the exercises as well as the diversity of those exercises, and this is consistent with what Abdul Mu'ti, Nadia (1999) and Hassan, Muhammad (2007) indicated that this type of training has a positive impact on the development of fitness components.

This is what the cross-training program exercises on defenses, both with hands and feet, have led to, and the resulting adaptations of rapid maxillary muscle contraction, and this is what Tudor indicated. Bompa 
(2000), Moranand G. H. meglynn (2001) showed that physiological adaptations lead to improved production of muscle strength of the juniors.

The researcher also attributes the development in agility, balance and flexibility to improving the muscular strength of the opposing muscles with the improvement of the elasticity of the muscles and their ability to move the working organs to the maximum extent through this cross-training program in addition to performing various exercises in which flexibility and elasticity exercises are used, whether in warm-up or inside Unity, as confirmed by Tudor o. Bompa (2000), Moranand G. H. meglynn (2001), argued that strong muscles protect the joints from injury due to their ability to move the limbs for a wide range of motion, in addition to the strength training exercises for the ligaments and what they contribute to the sense of movement in the muscles, joints and tendons from protecting the athlete from injury.

These results are consistent with the study of Zain, Ahmad (2016), the study of Al-Shennawi, Najla (2018), and the study of Al-Sayed Moawad (2018) in improving the level of special physical abilities as a result of implementing the proposed cross-training program.

It is also evident from Table (4) that there are statistically significant differences between the pre-measurement and the postmeasurement in favor of the post-measurement at a significance level of 0.05 in the degree of skill performance -under consideration-. The researcher attributed these differences to the application of the crosstraining program on the research sample, which includes various activities that have specificity in performance, derived from the type of performance practiced, as well as the use of different devices and tools than those used in the basic activity, in addition to the use of non-traditional training methods, taking into account Material capabilities when planning the program, as the rules and standardized scientific principles, balance and integration were adhered to when developing physical capabilities, Which had the greatest impact on improving the level of skill performance.

This is consistent with the results of the study of Rayhan, Ahmad (2018), the study of Ibrahim, Muhammad, and Diaa Ahmad (2018) and the study of Mahmoud, Musaad, Qandil, Al-Sayed, and AlMorshedy, Ahmed (2016) that the use of various exercises works to improve the level of skillful performance in the specialized activity. 
From the above it is clear that cross-training is one of the appropriate training methods that are consistent with the preparation period for juniors, especially as it allows the combination of the two transitional periods and general preparation, as well as providing time for the proper preparation of juniors. Thus, the differences in the level of physical abilities, mental toughness and the degree of skillful performance of junior aerobic gymnastics become clear to us due to cross training. This proves the validity of the research hypothesis which stated that "there are statistically significant differences between the pre and post measurements in mental toughness and the level of special physical abilities and the degree of skill performance of aerobic gymnasts and in favor of post measurement".

\section{Conclusions:}

Within the limits of the research sample and the methodology used, the researcher was able to draw the following:

1-The proposed cross-training program has a positive effect on improving the determinants of mental toughness, represented by (self-confidence - negative energy - attention control - visual perception control - motivation level - positive energy - direction control) of the experimental sample.

2-The proposed cross-training program has a positive effect on developing the special physical abilities (explosive strength - agility balance - flexibility) of the experimental sample.

3-The proposed cross-training program had a positive effect on improving the degree of skill performance of aerobic gymnasts under the age of 14 .

\section{Recommendations:}

Based on the findings of the study, the researcher recommends the following:

1-The use of the proposed cross-training program because of its advantages and effective impact in improving physical abilities and determinants of mental toughness and the degree of skill performance when planning training in aerobic gymnastics for juniors under 14 years.

2- Emphasis on the use of cross-training in gymnastics as one of the complementary aspects of the fitness program. 
3- Paying attention to psychological training programs to improve physical capabilities and determinants of mental toughness among athletes.

4- Conducting more similar studies to know the effect of cross-training on different skill difficulties and other age stages.

\section{References:}

\section{Arabic References:}

Ibrahim, Shaaban and Badr al-Din, Tariq. (2001). Psychological Factors in Achievement in Achievement, Issue 42.

Ibrahim, Mohammed Ahmed Abdullah, and Diaa Ahmed Talaat Abdullah. (2018). The effectiveness of cross-training on some skill variables for beginners table tennis. Journal of Comprehensive Education Research: Zagazig University - College of Physical Education for Girls No. 1 202-218. Retrieved from http://search.mandumah.com.sdl.idm.oclc.org/Record/1020411

Ismail, Magda Mohamed. Fouad, Jihan Mohamed. (2006). The effect of mind training

Jawed, Muhammad. (2004). The effect of using cross-training on job performance, architecture, architecture, architecture, Alexandria University.

Al-Hadidi, Rabih Othman Muhammad. (2011). Cross training on some educational abilities and toughness. Physical Education Research Journal: Zagazig University - College of Physical Education for Boys, Mag 45, Issue 85, 29-59. Retrieved from http://search.mandumah.com.sdl.idm.oclc.org/Rec/32901

Hassan, Zaki Mohamed. (2004). Cross-training is a recent trend in sports training, Egyptian Library, Alexandria.

Hassan, Muhammad (2007). The Effect of Using Cross Training on Capacity Development, Master Thesis, unpublished, College of Physical Education for Boys, Helwan University.

Rashad, Mervat Mohamed. (2006). The effect of hypoxic training on the endurance of dueling, and the phenomenon and beauty of respiration with mental toughness, Journal of Comprehensive Physical Education, College of Physical Education for Girls, Zagazig University, Volume Two, January.

Rehan, Ahmed Ali Al-Saeed. (2018). The effect of cross-training on the digital level of snatch leverage for emerging lifters. The Scientific Journal of Sport Sciences and Arts: Helwan University - College of Physical Education for Girls, Mag 51, 35 - 54. Retrieved from http://search.mandumah.com.sdl.idm.oclc.org/Record/903804

Zain, Ahmed Mohamed Mohamed. (2016). The effect of using the method of cross training on some general, physiological, and skill levels of 
boxing players. The Scientific Journal of Education and Sport Sciences: Helwan University - College of Physical Education for Boys, No. 77. 166-183. Retrieved from http://search.mandumah.com.sdl .idm.oclc.org / Record / 760306

Salem, Rehab Rashad. (2018). The effect of impact training on ability and skill level of aerobic gymnasts. Assiut Journal of Physical Education Sciences and Arts: Assiut University - Faculty of Physical Education, vol. 47, C4, 689-712. Retrieved from http://search.mandumah.com.sdl.idm.oclc.org/Record/1061678

Al-Sayed., Al-Sayed. Moawad. (2018). The effect of using cross-training in terms of biochemical indicators on some mathematical, physiological and skill variables of fencing players. Journal of the College of Education: Tanta University - College of Education, Volume 71, Issue 3, 162-204. Retrieved from http://search.mandumah.com.sdl.idm.oclc.org/Rec/978132

Al-Sayed. Mohamed Lotfy. , Mohammed Ashraf. (2003). Training in a varied manner and its effect on the ability of the player to jump up in volleyball, "published research, Journal of Applications Theories, Issue 47, College of Physical Education for Boys, Alexandria University.

Shimon, Muhammad Al-Arabi. (2001). Mental toughness and sports achievements, a conference of the Department of Sports Psychology, Faculty of Physical Education for Boys in Al-Haram, Heloun University.

Shimon, Muhammad Al-Arabi. (2007). Physiotherapy for the Department of Sports Psychology, College of Physical Education for Boys, Helwan University.

El-Shenawi, Naglaa. (2018). The effect of using cross-training method on some musical and physical biomechanical variables and the digital level of javelin throwers. Assiut Journal of Physical Education Sciences and Arts: Assiut University - Faculty of Physical Education, vol. 46, c 1, 286-311. Retrieved from http://search.mandumah.com.sdl.idm.oclc.org/Record/883024

Shawky, Najia Abdel Fattah. (2015). The effect of cross training on some sports and judo during the transition period. International Conference on Sport, Health and Life Sciences: Assiut University - Faculty of Physical Education, No. 4, Alexandria: Assiut University - Faculty of Physical Education, 1527 - 1559. 780596

Abdel Moati, Nadia Ali. (1991). The effect of intervening training on developing female students 'physical fitness components, College of Physical Education, Master Thesis, College of Physical Education for Women, Helwan University.

(EGF). (2018). Instructions for tournaments and mandates for all stages of aerobic gymnastics for the sports season 2018-2019. 
Mahmoud, Musaad, Qandil, Al-Sayed, and Al-Morshedy, Ahmed. (2016). The effect of a training program The cross-training has been voted on the level of skill performance of the skill of falling on the man from outside for the beginners of freestyle wrestling. The Scientific Journal of Education and Sports Sciences: Mansoura University - College of Physical Education, pp. 26, 77 - 99. Retrieved from http://search.mandumah.com.sdl.idm.oclc.org/Record/77857

Foreign References:

Abalo Núñez, R., Gutierrez-Sanchez, A., \& Vernetta Santana, M. (2013). Aerobic gymnastics injuries. Review article. Revista Internacional de Medicina y Ciencias de la Actividad Física y el Deporte, 13(49), 183198.

Abalo, R., Vernetta, M., \& Gutiérrez-Sánchez, A. (2013). Prevention of injuries to lower limbs using logistic regression equations in aerobic gymnastics. Medicina dello Sport, 66(2), 265-276.

Abalo-Núñez, R., Gutiérrez-Sánchez, A., Pérez, M. I., \& Vernetta-Santana, M. (2018). Injury prediction in aerobic gymnastics based on anthropometric variables. Science \& Sports, 33(4), 228-236.

Alves, C. R. R., Borelli, M. T. C., de Salles Paineli, V., de Almeida Azevedo, R., Borelli, C. C. G., Junior, A. H. L., .. \& Artioli, G. G. (2015). Development of a specific anaerobic field test for aerobic gymnastics. PloS one, 10(4), e0123115.

Brislin . G,M.S.,C.S.C.S., . (1998) .Improved performance through cross training techniques, winter sidelines.

Brislin, G. (1998). Improved performance through Cross training Techniques, winter Sidelines.

D'Anna, C., Tafuri, D., Forte, P., \& Paloma, F. G. (2019). Comparison of two pre-jump techniques for equal feet take off jump in aerobic gymnastics: a pilot study. Journal of Physical Education and Sport, 19(2), 1268-1275.

Fiona Hayes (1998).La Gula Completa Del Cross training, editorial paidotribo, Barcelona, Spain.

Gould, D., Dieffenbach , K., \& Moffett, A.(2002) . Psychological characteristics and their development in olympic champion journal of applied sport psychology, 17.

Hayley Merrett .(2004) .Volleyball Mental Toughness- How to spark that volleball fire in your players, ezine article, U.S.A.

International Gymnastics Federation (FIG). (2017).Code of Points. Aerobic Gymnastics 2017-2020, 155-22222p. Retrieved from http://www.figgymnastics.com/publicdir/rules/files/mag/CoP MAG 2017-

2020 ICl-e.pdf 
John Lefkowits, David R. Mc Duff, Corina Riismandel.(2003). Mental toughness training manual for soccer, United Kingdom: Article Sports Dynamics.

Jolly,Ray. (2003). Mental toughness, level III, Hockey coaching course kamatake state Hockey association, and Bangalore.

Mariana, M., \& Orlando, C. (2014). Performance Criteria in Aerobic Gymnastics-Impact on the Sportive Training. Procedia-Social and Behavioral Sciences, 117, 367-373.

Matt Fitzgerald (2010).The Case for Cross- training, 19 jan, Retrieved from http://www.running.competitor.com/2010/01/the- case-for-crosstraining-7917.

Moranand G . H . meglynn , (2001).cross Traing For sports . Human Kinetic books, san Francisco.

Pedersen, DM (2000). Perceived relative importance of psychological and physical factors in successful athletic performance. Percept mot sills .2000 fed: 90(1): 238-90.: 10769912 (Pub Med- indexed Medlin

Pop, C., \& Ciomag, V. (2014). The Influence of Aerobic Gymnastics on the Students' Body Image. Procedia-Social and Behavioral Sciences, 117, 129-135.

Pritchard,Keith.(2002).Psychological Characterictics of Male Jymnasts Differevces Petween Competitive Levels, J.S Portes, S.C.I, 8 (2).

Sellars ,Chris.(1997). Building self- confidence, coachwise puplish. England.

Simon C. Middleton, Herb W. Marsh, Andrew J. Martin, Garry E. Richards and clark perry .(2004) .Discovering Mental toughness: A Qualitative study of Mental toughness elite athletes, third international biennial, self research conference, self- concept, Motivation and identity: where to form here, july 4-7, Berlin, Germany.

Taylor , A, W (2000) .effect of Plyometric training on vertical jump performance long jump, sport medicine and physical fitness journal, Torino.

Tudor o. Bompa .2000) .total training for young champions ( proven conditioning programs for athletes ages 6 to 19), Human kinetics. 